\title{
Do we still need breast cancer screening in the era of targeted therapies and precision medicine?
}

\author{
Rubina Manuela Trimboli ${ }^{*}$ (D, Paolo Giorgi Rossi ${ }^{2}$, Nicolò Matteo Luca Battisti ${ }^{3,4}$, Andrea Cozzi ${ }^{1}$, Veronica Magni ${ }^{5}$, \\ Moreno Zanardo ${ }^{1}$ and Francesco Sardanelli ${ }^{1,6}$
}

\begin{abstract}
Breast cancer (BC) is the most common female cancer and the second cause of death among women worldwide. The 5-year relative survival rate recently improved up to 90\% due to increased population coverage and women's attendance to organised mammography screening as well as to advances in therapies, especially systemic treatments. Screening attendance is associated with a mortality reduction of at least $30 \%$ and a $40 \%$ lower risk of advanced disease. The stage at diagnosis remains the strongest predictor of recurrences. Systemic treatments evolved dramatically over the last 20 years: aromatase inhibitors improved the treatment of early-stage luminal BC; targeted monoclonal antibodies changed the natural history of anti-human epidermal growth factor receptor 2positive (HER2) disease; immunotherapy is currently investigated in patients with triple-negative BC; gene expression profiling is now used with the aim of personalising systemic treatments. In the era of precision medicine, it is a challenging task to define the relative contribution of early diagnosis by screening mammography and systemic treatments in determining BC survival. Estimated contributions before 2000 were $46 \%$ for screening and 54\% for treatment advances and after 2000,37\% and 63\%, respectively. A model showed that the 10-year recurrence rate would be $30 \%$ and $25 \%$ using respectively chemotherapy or novel treatments in the absence of screening, but would drop to $19 \%$ and $15 \%$ respectively if associated with mammography screening. Early detection per se has not a curative intent and systemic treatment has limited benefit on advanced stages. Both screening mammography and systemic therapies continue to positively contribute to BC prognosis.
\end{abstract}

Keywords: Breast neoplasms, Mammography, Cancer screening, Prognosis, Precision medicine

\section{Key points}

- The stage at diagnosis is still crucial in determining survival outcomes for breast cancer.

- Screening attendance is associated with a reduction of advanced-stage disease.

- Novel endocrine and anti-human epidermal growth factor receptor 2 (HER2)-targeted therapies have substantially improved survival.

\footnotetext{
* Correspondence: trimboli.rm@gmail.com

'Department of Biomedical Sciences for Health, Università degli Studi di Milano, Via Mangiagalli 31, 20133 Milan, Italy

Full list of author information is available at the end of the article
}

- Early diagnosis and personalised treatments synergistically contribute to improve prognosis.

- We do still need breast cancer screening in the era of precision medicine.

\section{Introduction}

Breast cancer is the most common female cancer worldwide, accounting for $30 \%$ of all new cancer diagnoses in women [1]. Social and economic trends are associated with a continuous increase in incidence rates by approximately $0.5 \%$ per year $[1,2]$. Ageing population, maternity delay and low parity, obesity and sedentary lifestyle - along with an escalation in the diffusion of

\section{Springer Open}

(c) The Author(s). 2020 Open Access This article is licensed under a Creative Commons Attribution 4.0 International License, which permits use, sharing, adaptation, distribution and reproduction in any medium or format, as long as you give appropriate credit to the original author(s) and the source, provide a link to the Creative Commons licence, and indicate if changes were made. The images or other third party material in this article are included in the article's Creative Commons licence, unless indicated otherwise in a credit line to the material. If material is not included in the article's Creative Commons licence and your intended use is not permitted by statutory regulation or exceeds the permitted use, you will need to obtain permission directly from the copyright holder. To view a copy of this licence, visit http://creativecommons.org/licenses/by/4.0/. 
breast cancer mammography screening - contributed to this increase in high-income countries [2].

Traditionally, survival outcomes are influenced by tumour size, nodal involvement, grade, hormone receptor (HR) and human epidermal growth factor receptor 2 (HER2) status. Although breast cancer remains the second leading cause of death among women after lung cancer, the 5-year relative survival rate in the United States has improved from $79 \%$ in 1984-1986 to $91 \%$ in 2008-2014 [3, 4]. Similar trends have been observed in Europe: in Italy, survival improved from 80\% in 1995 to $88 \%$ in 2010 [5].

As detailed by the timeline in Fig. 1, breast cancer care has substantially evolved over the past fifty years, with non-negligible changes in screening and diagnostics, histological analysis, surgery, radiation therapy, and systemic treatments. The implementation and diffusion of screening mammography and various improvements in systemic anticancer treatments have been the main drivers of these changes [6]. In Europe, 63.9 million women had access to population-based breast cancer screening in 2016 compared with 54.4 million in 2007, with $88 \%$ of the estimated target population completing rollout, compared with $41 \%$ in 2007 . Nevertheless, a wide geographical variability in invitation coverage still exists [7]. Similarly, in the 2000s, the use of chemotherapy has increased up to $80 \%$, and the use of tamoxifen up to $50 \%$ for patients with oestrogen receptor-positive tumours: nowadays, in Italy, about $50 \%$ of patients undergoing surgery for stage I-III breast cancer receive systemic treatments that include targeted therapy [8], while in the United States targeted therapy is administered to almost $20 \%$ of patients with stage I-II disease and to over $60 \%$ of those with stage III disease [9]. Of note, along with traditional prognostic factors, gene expression profiling is now increasingly adopted, aiming to personalise therapeutic approaches and escalate or de-escalate systemic treatments [10]. In this complex framework, an evaluation of the impact of screening and systemic treatments on breast cancer prognosis looks challenging: their relative contribution may substantially differ across countries with different screening attendance rate and access to anticancer treatments.

Benefits deriving from screening and early diagnosis may become questionable when considering the efficacy of current systemic treatment options. In a theoretical model, a break-even point can be hypothesised when the advantages of early diagnosis by screening are nullified by the efficacy of individualised therapies. Nonetheless, detecting breast cancer before it is no longer curable should still be considered an advantage for the patient, since it remains unlikely that currently available therapies could be so effective without an early diagnosis. Any modification to this balance relies on the potential of systemic treatments to kill cancer cells at any stage, reducing or nullifying the screening benefit.

This critical review highlights the major landmark improvements in mammography screening and systemic treatment, to appraise their impact on breast cancer prognosis and to question the role of breast cancer screening in the era of precision medicine.

\section{Mammography screening}

Mammography screening was introduced in 1956 for the "detection of early cancer of the breast" [11]. In the 1970s, several randomised controlled trials confirmed a beneficial improvement of mammography screening on breast cancer mortality [12]. Such benefit pertains to women aged 50 to 74 years and is maximal, about $30 \%$, in those aged 60 to 69 years [13-16]. Mammography screening programs have the general aim of reducing breast cancer-specific mortality both by minimising the risk of diagnosing breast cancer in the advanced stage and by maximising the efficacy and safety of anticancer treatments and their impact on prognosis.

The first $\mathrm{x}$-ray units dedicated to mammography used $x$-ray film and paired fluorescent screens to capture the image, in the so-called screen-film mammography, which has been gradually replaced since the early 2000 s by digital mammography units. In 2005, a landmark study by Pisano et al. [17] compared the diagnostic accuracy of digital and screen-film mammography in 42 , 760 asymptomatic women. At receiver operating characteristic analysis over the entire population, the areas under the curve (AUCs) of the two methods differed by a non-significant 0.03 . However, the digital technique was significantly superior among women over 50 (0.15 AUC difference), among women having heterogeneously or extremely dense breasts (0.11 AUC difference), and among women being in pre- or perimenopause $(0.15$ AUC difference). Digital mammography allowed also to deliver a lower radiation dose and resulted in easier image storage and subsequent access. Its initially higher costs dwindled quite quickly, its uptake steadily increased [18, 19]. By 2015, 96\% of all mammography units in the United States had gone digital [20].

The incidence of advanced-stage tumours in the target population is a specific proxy indicator of screening efficacy, given the absence of confounding effects of treatments at the time of diagnosis. However, studies on this topic have adopted different thresholds in defining the severity of the diseases and are characterised by poor to fair overall quality. Nevertheless, a meta-analysis of trials combined their results - including the most severe disease categories available - and showed a significant reduction in the risk of advanced-stage disease for women 


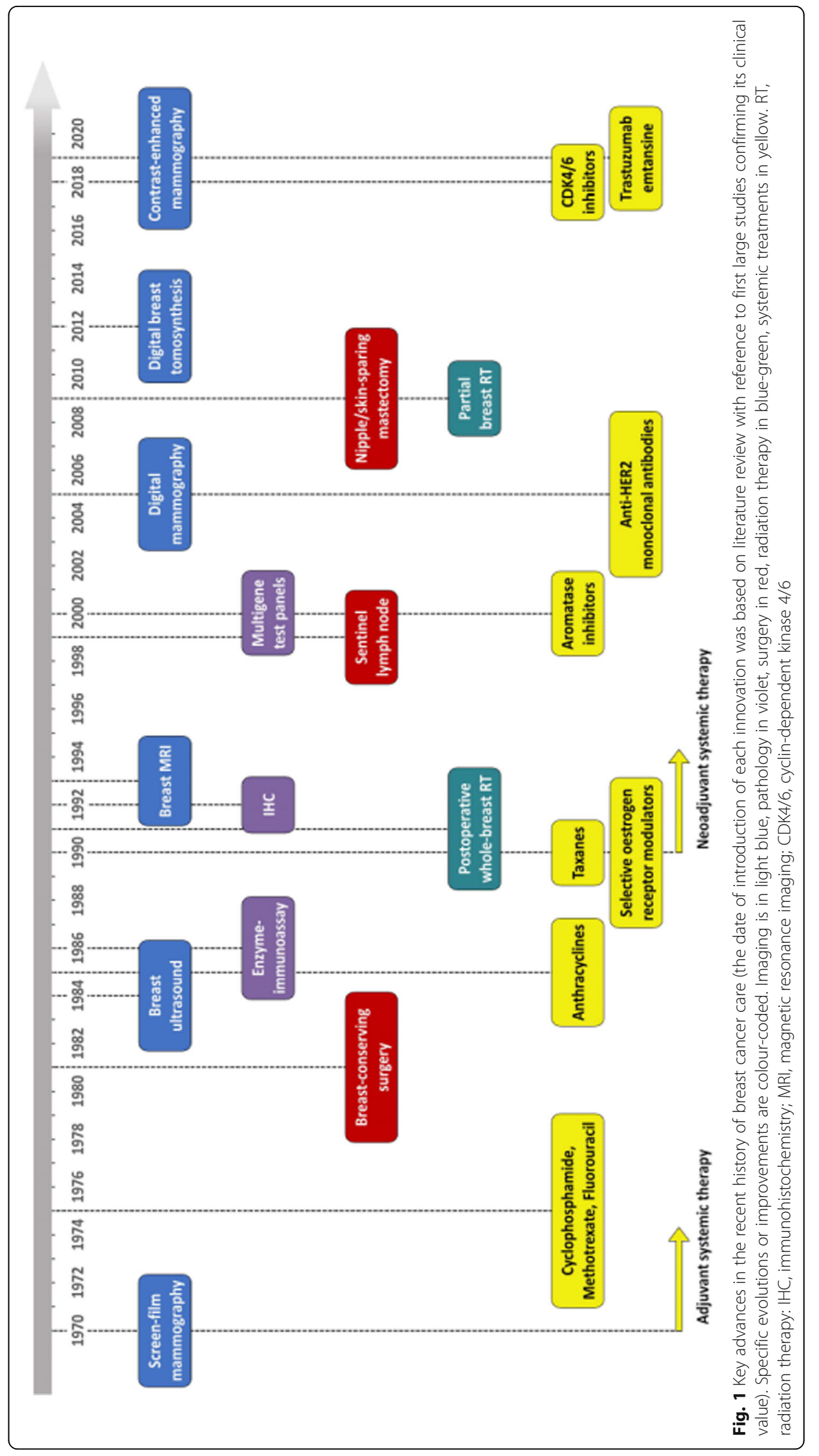


aged 50 years or older (relative risk $0.62,95 \%$ confidence interval $[\mathrm{CI}]$ 0.46-0.83) randomly assigned to undergo screening: this benefit was however not seen in women aged 39 to 49 years [14].

More recently, a prospective Italian cohort study was conducted on 413,447 women undergoing screening in the 1990s and followed up for 13 years as part of the IMPACT project [21]. Screening attendance was positively associated with: (a) a 39\% reduction of the incidence of pT2-T4 lesions (66.3\% versus $108.6 \%$, incidence rate ratio $0.61,95 \%$ CI $0.57-0.66$ ), including a $28 \%$ reduction of pT2 lesions and a $68 \%$ reduction of pT3-T4 lesions; (b) a $28 \%$ reduction in the incidence of stage II-IV disease (130.1\%o versus $180.6 \%$, incidence rate ratio $0.72,95 \%$ CI $0.68-0.76$ ), including a $35 \%$ reduction of stage IIB, a $43 \%$ reduction of stage III, and a $73 \%$ reduction of stage IV. Notably, patients undergoing screening also benefited from a $17 \%$ reduction in the incidence of poorly differentiated carcinomas and from a 50\% increase of breast-conserving surgery rates. These results were also confirmed following adjustments to exclude self-selection bias, a significant reduction in the use of mastectomy being also observed [22].

Another interesting large population study - including 549,091 women across nine Swedish counties [23] - was conducted to evaluate the impact of screening mammography on breast cancer mortality. The study used an analytic strategy focusing on the incidence of fatal breast cancers within 10 years from the date of diagnosis, whereas other studies had been retroactively considering 10 years from the date of death. Women who attended mammography screening had a significant $41 \%$ reduction in their risk of dying of breast cancer within 10 years (relative risk $0.59,95 \%$ CI $0.51-0.68$ ) and a $25 \%$ reduction in the rate of advanced breast cancer (relative risk 0.75 , 95\% CI 0.66-0.84), regardless of the recent improvements in systemic treatments.

In 2019, the American Cancer Society and the National Cancer Institute published cancer treatment and survivorship statistics in the United States. Most patients (44\%) were diagnosed with stage I disease, 30\% with stage II, 9\% with stage III and 5\% with stage IV. The 5year breast cancer relative survival ranged from approximately $100 \%$ for stage I disease to $26 \%$ for stage IV breast cancer [9]. Interestingly, in 2018 Mariotto et al. [24] provided the first population-based summaries of the risk of breast cancer recurrence in United States women, using cancer registry disease-specific survival: stage remained the strongest predictor of the risk of recurrence, along with age (60-74 years) and HR-negative status. Thus, we can still affirm that tumour stage has a substantial impact on prognosis and on the risk of disease recurrence.

\section{Systemic treatments}

Chemotherapy has been used in the adjuvant setting since the early 1970s when landmark studies in the United States and in Italy documented a benefit of regimens such as L-phenylalanine mustard or the combination of cyclophosphamide, methotrexate and 5fluorouracil (CMF) in patients with node-positive breast cancer $[25,26]$. In the 1980 s and 1990 s, anthracyclines and taxanes proved to be more effective than CMF [27]; in the meantime, tamoxifen was found to substantially improve the survival of women with HR-positive tumours [28], and later on, aromatase inhibitors (AIs) proved to further improve outcomes in postmenopausal patients. During the 2000s, anti-HER2 therapies were developed as one of the first targeted systemic treatment options, changing dramatically the management and prognosis of HER2-positive breast cancer; in the same decade, genome expression profiling was deployed in routine practice, further improving the personalisation of breast cancer treatments [29]. Nonetheless, patient selection remains crucial to maximise efficacy and safety of systemic treatments. The current standard of care for different disease subtypes is summarised below.

\section{Luminal breast cancer}

The introduction of AIs has been a key improvement in the management of HR-positive, HER2-negative breast cancer $[9,30]$. Nowadays, AIs are standard of care for postmenopausal women, based on several studies that have documented better recurrence-free survival and disease-specific mortality in women treated with AIs compared with tamoxifen [19]. Two large phase III studies (the SOFT and TEXT studies) confirmed the role of AIs also for premenopausal patients and/or with highrisk disease, along with ovarian function suppression justified by a recurrence-free survival benefit [31]. An extended course of adjuvant endocrine therapy may also further improve outcomes, especially following upfront use of tamoxifen [32-39], since late recurrences remain a relevant issue for patients with luminal breast cancer [40]. Cyclin-dependent kinase 4/6 inhibitors are also being investigated in the adjuvant setting in several clinical trials [41-44], which might in due course change the current treatment paradigm in this setting.

\section{HER2-positive breast cancer}

Targeted agents are the foundation of precision medicine, which involves the use of drugs interfering with specific molecular alterations that drive tumour growth and spread: for example, targeted anti-HER2 agents have radically changed the natural history and prognosis of HER2-positive disease. The use of the anti-HER2 monoclonal antibody trastuzumab for 1 year, along with chemotherapy, is now standard of care for tumours with 
a size of $5 \mathrm{~mm}$ or greater and for tumours of any size with nodal involvement, based on the substantial disease-free and overall survival benefits that have been reported when compared with the use of chemotherapy alone (disease-free survival, hazard ratio for recurrence 0.60, 95\% CI 0.50-0.71; overall survival, hazard ratio for mortality $0.66,95 \%$ CI $0.57-0.77$ ) [45]. Moreover, additional benefits have been documented with adjuvant treatment escalation in higher-risk tumours: adding novel anti-HER2 agents, such as pertuzumab and neratinib, improves disease-free survival in women with nodepositive disease [46] and recurrence rates in patients with large and HR-positive, HER2-positive tumours [47]. On the other hand, adjuvant treatment de-escalation has been investigated for patients with a lower risk of breast cancer recurrence in order to minimise the impact of systemic treatment on safety and quality of life [48]. Response to preoperative systemic treatment is a prognostic factor in patients with HER2-positive breast cancer, with better survival outcomes in patients without invasive disease at the surgical specimen, defined as ypT0/Tis ypN0 [49]. Therefore, neoadjuvant systemic treatment remains a very reasonable approach [50] and the addition of pertuzumab to trastuzumab to chemotherapy has become a standard of care, considering the improvements in pathological complete response rates $[51,52]$.

\section{Triple-negative breast cancer}

The systemic treatment of HR-negative and HER2negative breast cancer is still largely limited to the use of chemotherapy. Adjuvant chemotherapy remains standard of care for patients with triple-negative breast cancers, either of $5 \mathrm{~mm}$ or greater or with pathologically involved lymph nodes [53]. In this specific setting, several trials are currently investigating the role of novel agents such as immunotherapy, which aims to boost the immune response against the tumour [54-56]. Neoadjuvant chemotherapy is the preferable approach in patients with locally advanced disease or in those who are not candidates for upfront surgery. Nonetheless, the role of neoadjuvant systemic therapy has also expanded, aiming to improve surgical operability and cosmetic outcomes but also to test the chemosensitivity of breast cancer in vivo, which has relevant prognostic implications $[49,57]$.

\section{Gene expression profiling}

Genomics and the ability to evaluate simultaneously the expression of multiple genes led to the development of gene expression profiles, which have been validated to identify patients with a higher risk of disease recurrence who may benefit from the use of adjuvant chemotherapy. Oncotype Dx has been validated both as a prognostic and a predictive tool, although Mammaprint [58], EndoPredict [59, 60], Breast Cancer Index [61] and
Predictor Analysis of Microarray 50 (PAM50) [62, 63] may also be used. Oncotype Dx identifies women with node-negative, HR-positive breast cancer whose prognosis is so favourable that the absolute benefit of chemotherapy is likely to be very low. Patients with HRpositive node-negative cancers derive substantial benefit from chemotherapy when their score is high, typically higher than 25. On the other hand, if their score is low or midrange (lower than 25), adding chemotherapy to endocrine treatment for women over 50 showed no benefit, although younger women may experience some benefit $[64,65]$. While the use of Oncotype Dx in patients with node-positive, HR-positive breast cancer is supported by less robust evidence, it has been considered [66] and is currently being investigated [67].

\section{The winning weapon: mammography screening plus systemic treatments}

Defining the relative contribution of screening mammography and systemic treatments to improve breast cancer outcomes is a challenging task. The increasing use of screening and the gradual implementation of more effective therapeutic approaches occurred over nearly the same period since the 1970s. In the meantime, breast surgery has also evolved, along with the introduction of sentinel lymph node biopsy and radiation therapy. Overall, each of all these developments substantially contributed to improve patient outcome.

The Cancer Intervention and Surveillance Modelling Network used modelling techniques to provide estimates of the contributions of screening mammography and adjuvant treatment to the reduction of breast cancer mortality in the United States from 1975 to 2000 [68]. Seven independent statistical models were developed and yielded similar qualitative conclusions, namely that "the decline in mortality rate can be explained by a combination of screening and therapy and not by either one alone". The proportion of the total reduction in the rate of death from breast cancer attributed to screening varied in the seven models from $28 \%$ to $65 \%$ (median $46 \%$ ). On the other hand, the contribution of systemic therapy including chemotherapy and tamoxifen varied from $35 \%$ to $72 \%$ (median 54\%): differences in these estimates reflect the mutual interaction between the two interventions [68].

Saadatmand et al. [69] investigated - in a large population-based cohort study - whether tumour stage at diagnosis still influences survival in the context of the current therapeutic approaches. This prospective nationwide population-based study was conducted in the Netherlands and included 173,797 women diagnosed with breast cancer, with two cohorts being identified according to the year of breast cancer diagnosis. A total of 80,228 patients were diagnosed with breast cancer from 
1999 to 2005, while 93,569 from 2006 to 2012: in this second period - following national guidelines - systemic therapy was more widely used. At univariate and multivariate analyses, tumour stage and nodal status significantly influenced overall and relative survival in both cohorts. Relative survival rates ranged from almost $100 \%$ in both cohorts for in situ tumours to $57 \%$ and $59 \%$ for T4 tumours in the older and more recent cohort, respectively. At multivariate analysis, breast-conserving treatment (more frequently pursued in the 2006-2012 cohort) resulted in a significant survival benefit compared with mastectomy, whereas lymph node dissection (less frequently pursued) was associated with a significantly worse overall survival. The wider use of chemotherapy in the 2006-2012 cohort conferred a hazard ratio for death of 0.86 (95\% CI $0.80-0.92)$. These largescale results clearly demonstrate that while the use of chemotherapy may impact on survival, tumour size at diagnosis still matters. Authors concluded that "in the current era of effective systemic therapy, diagnosis of breast cancer at an early stage remains vital" [69]. Moreover, considering United States women diagnosed with breast cancer at age 60-74, summaries of the risk of breast cancer recurrence showed a 5-year recurrence rate of $2.5 \%, 9.6 \%$ and $34.5 \%$ for stages I, II and III HRpositive breast cancers, and a 5 -year recurrence rate of $6.5 \%, 20.2 \%$ and $48.5 \%$ for stages I, II and III HRnegative breast cancers [24].

Another study from the United States [6] also assessed to what extent digital mammography screening and novel systemic therapies contributed to the improvement in breast cancer mortality in different disease subtypes from 2000 to 2012: its results are summarised in Table 1. Complex simulation models from the Cancer Intervention and Surveillance Network projecting breast cancer mortality trends for women aged 30 to 79 years estimated a $12 \%$ difference (model range, 10-16\%) in the overall disease-specific mortality reduction between 2000 (37\%, model range, 27-42\%) and 2012 (49\%, model range, $39-58 \%)$. The relative contribution to the decrease in overall breast cancer mortality in 2012 was $37 \%$ (model range, 26-51\%) for screening and 63\% (model range, 49-74\%) for treatment. Of the 37\% mortality reduction associated with screening in 2012, 33\% (model range, 29-48\%) was associated with screening advances before 2000 and $4 \%$ (model range, 1-8\%) after 2000 (the shift from screen-film to digital mammography was relatively less relevant than previous improvements when considering the conspicuous advancements in therapeutic options). Similarly, of the $63 \%$ mortality reduction associated with treatments in $2012,32 \%$ was associated with chemotherapy, $27 \%$ with hormone therapy and $4 \%$ with trastuzumab. Of the $31 \%$ mortality reduction (model range, 23-37\%) associated with chemotherapy, 9\% (model range, 7-14\%) was associated with chemotherapy advances after 2000 (largely taxanes). Of the $27 \%$ mortality reduction (model range, 18-36\%) associated with hormone therapy, 7\% (model range, 2$12 \%)$ was associated with advances in hormone therapy after 2000 (largely from AIs) [6].

Subtype analyses also demonstrated significant variations in the relative contribution of screening and treatment to the mortality reduction in different tumour molecular subtypes. The largest benefit of screening (48\%, model range, 38-57\%) was found in the triple-negative tumour breast cancer cohort, while the largest benefit of treatment (69\%, model range, 59-77\%) was documented in luminal tumours. According to this model-based analysis, both screening and treatment contributed and still contribute to the improvement in breast cancer mortality, with progressively greater contributions of therapeutic advances in the last decades [6].

The relative contribution associated with mammography screening and advances in systemic therapies to the reduction in the recurrence rate is simulated in Figs. 2 and 3. Here, four scenarios combine variably the contribution of screening mammography and chemotherapy or novel systemic treatments (i.e. AIs and targeted agents). In this simulation, stage distribution was derived from Puliti et al. [21], considering attenders and non-attenders to mammography screening and adjusted for self-selection. A $5 \%$ overdiagnosis attributed to population screening has been considered when it was included in the scenario. Ten-year disease-specific survival

Table 1 Association of screening and treatment with breast cancer mortality in US women from 2000 to 2012

\begin{tabular}{|c|c|c|c|c|c|c|c|}
\hline & \multicolumn{3}{|c|}{ Mortality reduction compared to $1975(\%)$} & \multicolumn{4}{|c|}{ Contribution to the difference in mortality reduction in 2012 versus 2000 (\%) } \\
\hline & $\ln 2000^{a}$ & $\ln 2012^{b}$ & Difference & Screening advances & Chemotherapy advances & Hormone therapy advances & Trastuzumab \\
\hline Overall & 37 & 49 & 12 & 17 & 38 & 29 & 15 \\
\hline $\mathrm{ER}+/ \mathrm{HER} 2-$ & 39 & 51 & 12 & 19 & 39 & 42 & 0 \\
\hline $\mathrm{ER}+/ \mathrm{HER} 2+$ & 39 & 58 & 19 & 12 & 22 & 25 & 41 \\
\hline ER-/HER2+ & 29 & 45 & 16 & 11 & 32 & 0 & 57 \\
\hline ER-/HER2- & 29 & 37 & 8 & 22 & 78 & 0 & 0 \\
\hline
\end{tabular}

Relative to the estimated baseline rate of 64 deaths (model range, 56-73) per 100,000 women in 2000; ${ }^{\text {b }}$ Relative to the estimated baseline rate of 63 deaths (model range, 54-73) per 100,000 women in 2012. ER oestrogen receptor, HER2 human epidermal growth factor receptor 2. Source: Plevritis et al. [6] 


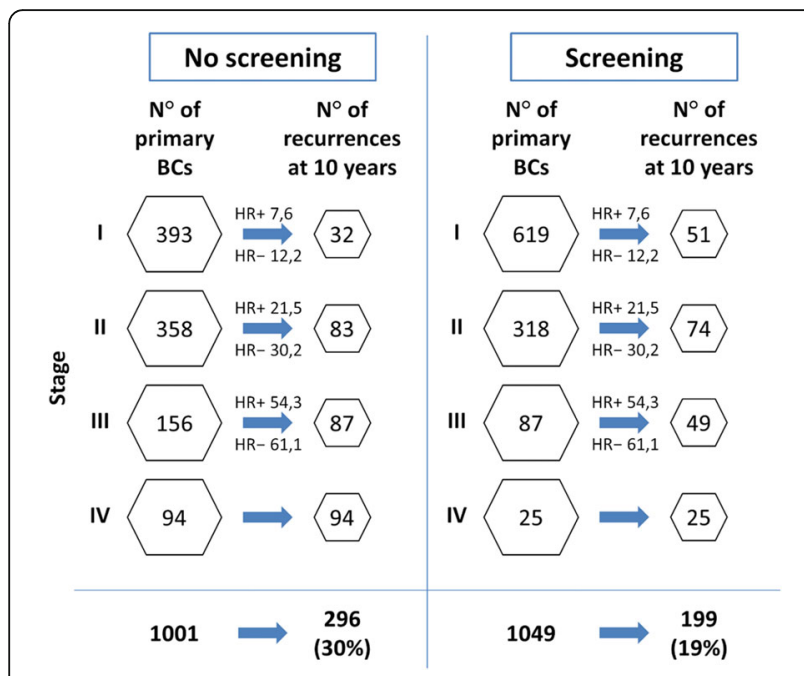

Fig. 2 Effect of screening and chemotherapy on breast cancer recurrences among women aged 60 to 74 years, diagnosed with breast cancer between 1992 and 1999. Stage distribution was derived from Puliti et al. [21] considering attenders and nonattenders to screening mammography; $5 \%$ overdiagnosis attributed to screening mammography is taken into account. HR+ and HRrecurrences are back-calculated from Mariotto et al. [24]. The worst scenario reflects the absence of mammography screening and the use of chemotherapy alone. BCs, breast cancers; HR+, hormone receptor-positive breast cancers; HR-, hormone receptor-negative breast cancers

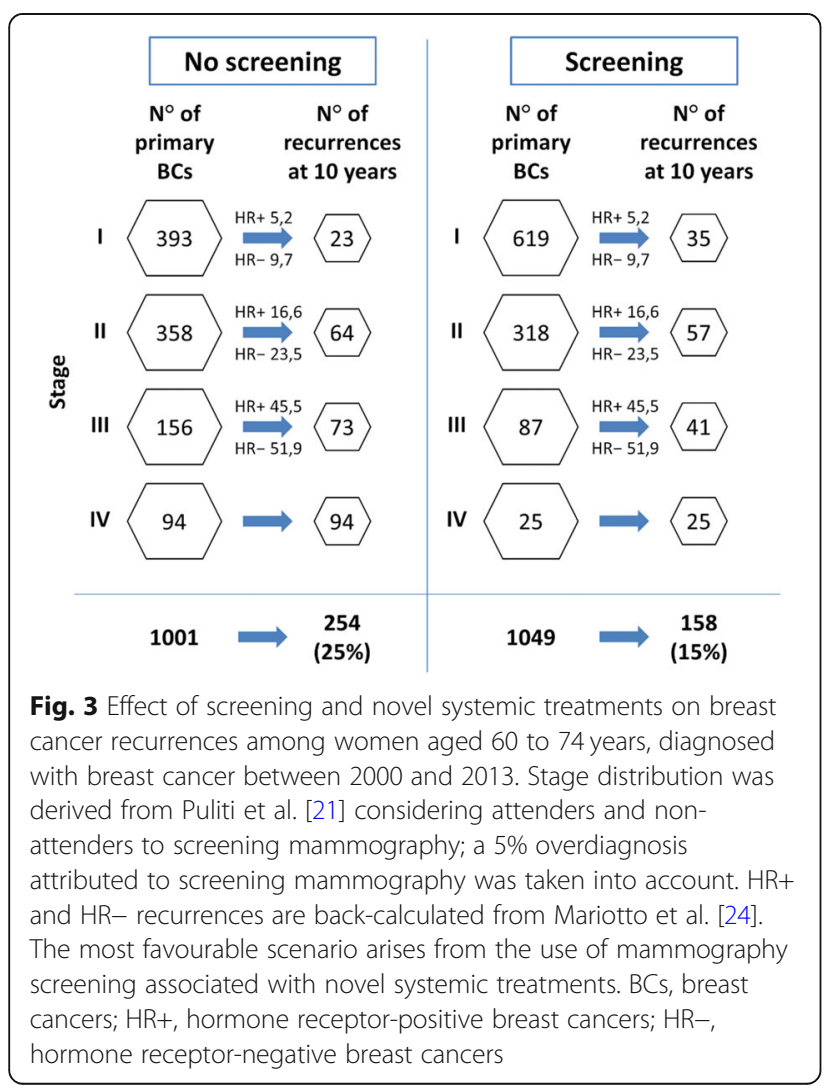

for HR-positive and HR-negative cancers was retrieved from Mariotto et al. [24], based on women aged 60-74 years treated in the 1992-1999 period or in the 20002013 period, when more advanced therapies were available. This simulation shows how combining screening mammography and novel systemic agents represent the most favourable scenario with the lowest number of recurrences, also detailing how the recurrence rate at 10 years would be $30 \%$ for chemotherapy without screening and $19 \%$ for chemotherapy with screening, $25 \%$ for novel treatments without screening and 15\% for novel treatments with screening.

Two important aspects should however be considered in the analysis of the evolution of screening and systemic therapies. Despite the widespread use of screening mammography, the introduction of digital techniques represents the most important technical advancement: of note, tomosynthesis has become the technique of choice for symptomatic women and those who are recalled for further assessment after a screening mammogram [13]. Conversely, the evidence in favour of its use as a firstlevel screening tool is still not sufficient in terms of reduction of interval cancer rate (possibly due to an underlying rate of overdiagnosis [70-73]) and European guidelines [13] have advised against its use for population-based screening programs. On the other hand, increasingly effective novel systemic treatment options are being introduced as a standard of care and gene expression profiling is progressively enabling better decision-making.

This is once again a turning point. In case of further outcome improvements, most of the contribution would then be attributable to better systemic treatments. Nevertheless, MRI [74] and other novel imaging modalities, such as contrast-enhanced mammography [75-77] could come to be considered screening tools in selected populations, their contribution being also promising. Furthermore, a recent survey among members of the European Society of Radiology [78] showed that there are high expectations on the use of artificial intelligence $[79,80]$. Dedicated algorithms will focus on personalised risk prediction and prognosis [81] and machine/deep learning software has already shown high performance in interpreting screening mammography. Finally, the availability of molecular analyses on liquid biopsy could represent another promising option [82, 83].

However, further widespread benefits in breast cancer outcomes are expected to become ever slimmer in the context of the efficacy of the current standard treatments: research efforts will therefore need to focus on the role of precision medicine. Once outcomes are maximal in the overall breast cancer patient population, improvements might indeed be sought in selected populations and especially in those with poor prognosis. 


\section{Conclusions}

The increasing use of screening mammography and improvements in systemic treatments have substantially reduced breast cancer mortality over the last two decades. However, defining their relative contribution to improving outcomes remains a challenging task. Early detection is crucial if followed by effective treatments. Nonetheless, treatments are still less effective in the case of advanced-stage disease. Prevention and early diagnosis contributed to almost half of the reduction in breast cancer mortality, whereas the rest is due to advances in breast cancer treatment, whose role and contribution has become predominant since the early 2000s. In the era of precision medicine, early detection remains crucial and a delay in breast cancer diagnosis, with a tumour detected at an advanced stage, can substantially increase mortality. Screening mammography and systemic anticancer treatment are synergistic in improving breast cancer prognosis.

\section{Abbreviations}

Als: Aromatase inhibitors; AUC: Area under the curve; Cl: Confidence interval; CMF: Cyclophosphamide, methotrexate, and 5-fluorouracil; HER2: Human epidermal growth factor receptor 2; HR: Hormone receptor

\section{Authors' contributions}

All authors contributed to the conception and design of this work as well as to the writing and revision phases of the manuscript. All authors read and approved the final manuscript.

\section{Funding}

Paolo Giorgi Rossi participated thanks to the Innovative Partnership for Action Against Cancer (iPAAC) EC funded project.

\section{Availability of data and materials}

Not applicable.

\section{Ethics approval and consent to participate}

Not applicable.

\section{Consent for publication}

Not applicable.

\section{Competing interests}

R. M. Trimboli, P. Giorgi Rossi, N. M. L. Battisti, A. Cozzi, V. Magni, and M. Zanardo all declare that they have no conflicts of interest and nothing to disclose. F. Sardanelli declares to have received grants from or to be a member of the speakers' bureau/advisory board for Bayer Healthcare, Bracco Imaging, and General Electric.

\section{Author details}

${ }^{1}$ Department of Biomedical Sciences for Health, Università degli Studi di Milano, Via Mangiagalli 31, 20133 Milan, Italy. ${ }^{2}$ Epidemiology Unit, Azienda USL-IRCCS di Reggio Emilia, Via Amendola 2, 42122 Reggio Emilia, Italy. ${ }^{3}$ Breast Unit-Department of Medicine, The Royal Marsden NHS Foundation Trust, Downs Road, Sutton, London SM2 5PT, UK. ${ }^{4}$ Breast Cancer Research Division, The Institute of Cancer Research, 15 Cotswold Road, Sutton, London SM2 5NG, UK. ${ }^{5}$ Medical School, Università degli Studi di Milano, Via Festa del Perdono 7, 20122 Milan, Italy. ${ }^{6}$ Unit of Radiology, IRCCS Policlinico San Donato, Via Morandi 30, 20097 San Donato Milanese, Italy.
Received: 17 July 2020 Accepted: 20 August 2020

Published online: 25 September 2020

\section{References}

1. Siegel RL, Miller KD, Jemal A (2019) Cancer statistics, 2019. CA Cancer J Clin 69:7-34. https://doi.org/10.3322/caac.21551

2. Bray F, Ferlay J, Soerjomataram I, Siegel RL, Torre LA, Jemal A (2018) Global cancer statistics 2018: GLOBOCAN estimates of incidence and mortality worldwide for 36 cancers in 185 countries. CA Cancer J Clin 68:394-424. https://doi.org/10.3322/caac.21492

3. Hendrick RE, Baker JA, Helvie MA (2019) Breast cancer deaths averted over 3 decades. Cancer 125:1482-1488. https://doi.org/10.1002/cncr.31954

4. Howlader N, Noone AM, Krapcho M et al. (eds). SEER Cancer Statistics Review, 1975-2017, National Cancer Institute, Bethesda, MD. https://seer. cancer.gov/csr/1975_2017/. Accessed 31 August 2020

5. Coviello V, Buzzoni C, Fusco M et al (2017) Survival of cancer patients in Italy. Epidemiol Prev 41:1-244. https://doi.org/10.19191/EP17.2S1.P001.017

6. Plevritis SK, Munoz D, Kurian AW et al (2018) Association of screening and treatment with breast cancer mortality by molecular subtype in US women, 2000-2012. JAMA 319:154-164. https://doi.org/10.1001/jama.2017.19130

7. Basu P, Ponti A, Anttila A et al (2018) Status of implementation and organization of cancer screening in the European Union member statessummary results from the second European screening report. Int J Cancer 142:44-56. https://doi.org/10.1002/ijc.31043

8. Mangone L, Mancuso P, Tagliabue G et al (2019) Neoadjuvant therapy for breast cancer. Tumori 105:488-493. https://doi.org/10.1177/ 0300891619869505

9. Miller KD, Nogueira L, Mariotto AB et al (2019) Cancer treatment and survivorship statistics, 2019. CA Cancer J Clin 69:363-385. https://doi.org/10. 3322/caac.21565

10. Curigliano G, Burstein HJ, Winer EP et al (2017) De-escalating and escalating treatments for early-stage breast cancer: the St. Gallen international expert consensus conference on the primary therapy of early breast cancer 2017. Ann Oncol 28:1700-1712. https://doi.org/10. 1093/annonc/mdx308

11. Cohen JG, Ingleby H, Moore L (1956) Can mass x-ray surveys be used in detection of early cancer of the breast? J Am Med Assoc 161:1069-1071. https://doi.org/10.1001/jama.1956.62970110003010a

12. Frigerio A, Sardanelli F, Podo F (2017) Radiological screening of breast cancer: evolution. In: Veronesi U, Goldhirsch A, Veronesi P et al (eds) Breast Cancer. Springer International Publishing, Cham, pp 171-203

13. Schünemann HJ, Lerda D, Quinn C et al (2020) Breast cancer screening and diagnosis: a synopsis of the European breast guidelines. Ann Intern Med 172:46-56. https://doi.org/10.7326/M19-2125

14. Nelson HD, Pappas M, Cantor A et al (2016) Harms of breast cancer screening: systematic review to update the 2009 U.S. Preventive Services Task Force recommendation. Ann Intern Med 164:256-267. https://doi.org/ 10.7326/M15-0970

15. Nelson HD, Fu R, Cantor A et al (2016) Effectiveness of breast cancer screening: systematic review and meta-analysis to update the 2009 U.S. Preventive Services Task Force recommendation. Ann Intern Med 164:244255. https://doi.org/10.7326/M15-0969

16. Klarenbach S, Sims-Jones N, Lewin G et al (2018) Recommendations on screening for breast cancer in women aged 40-74 years who are not at increased risk for breast cancer. CMAJ 190:E1441-E1451. https://doi.org/10. 1503/cmaj.180463

17. Pisano ED, Gatsonis C, Hendrick E et al (2005) Diagnostic performance of digital versus film mammography for breast-cancer screening. N Engl J Med 353:1773-1783. https://doi.org/10.1056/NEJMoa052911

18. Sardanelli F, Fallenberg EM, Clauser P et al (2017) Mammography: an update of the EUSOBI recommendations on information for women. Insights Imaging 8:11-18. https://doi.org/10.1007/s13244-016-0531-4

19. Sardanelli F, Aase HS, Álvarez M et al (2017) Position paper on screening for breast cancer by the European Society of Breast Imaging (EUSOBI) and 30 national breast radiology bodies from Austria, Belgium, Bosnia and Herzegovina, Bulgaria, Croatia, Czech Republic, Denmark, Estonia, Finland, France, Germany, Greece, Hungary, Iceland, Ireland, Italy, Israel, Lithuania, Moldova, The Netherlands, Norway, Poland, Portugal, Romania, Serbia, Slovakia, Spain, Sweden, Switzerland and Turkey. Eur Radiol 27:2737-2743. https://doi.org/10.1007/s00330-016-4612-z 
20. Hendrick RE, Ikeda DM, Miyake KK (2017) Mammography acquisition. In: Ikeda DM, Miyake KK (eds) Breast imaging: the requisites, 3rd edn. Elsevier, St. Louis, pp 30-75

21. Puliti D, Bucchi L, Mancini S et al (2017) Advanced breast cancer rates in the epoch of service screening: The 400,000 women cohort study from Italy. Eur J Cancer 75:109-116. https://doi.org/10.1016/j.ejca.2016. 12.030

22. Zorzi M, Puliti D, Vettorazzi M et al (2006) Mastectomy rates are decreasing in the era of service screening: a population-based study in Italy (1997-2001). Br J Cancer 95:1265-1268. https://doi.org/10.1038/sj. bjc.6603405

23. Duffy SW, Tabár L, Yen AM et al (2020) Mammography screening reduces rates of advanced and fatal breast cancers: Results in 549,091 women. Cancer 126:2971-2979. https://doi.org/10.1002/cncr.32859

24. Mariotto AB, Zou Z, Zhang F et al (2018) Can we use survival data from cancer registries to learn about disease recurrence? the case of breast cancer. Cancer Epidemiol Biomarkers Prev 27:1332-1341. https://doi.org/10. 1158/1055-9965.EPI-17-1129

25. Bonadonna G, Brusamolino E, Valagussa P et al (1976) Combination chemotherapy as an adjuvant treatment in operable breast cancer. N Engl J Med 294:405-410. https://doi.org/10.1056/NEJM197602192940801

26. Fisher B, Carbone P, Economou SG et al (1975) L-phenylalanine mustard ( LPAM) in the management of primary breast cancer. N Engl J Med 292:117122. https://doi.org/10.1056/NEJM197501162920301

27. Munzone E, Curigliano G, Burstein HJ et al (2012) CMF revisited in the 21st century. Ann Oncol 23:305-311. https://doi.org/10.1093/annonc/mdr309

28. (1998) Tamoxifen for early breast cancer: an overview of the randomised trials. Early Breast Cancer Trialists' Collaborative Group. Lancet 351:14511467. https://doi.org/10.1016/S0140-6736(97)11423-4

29. Andre F, Pusztai L (2006) Molecular classification of breast cancer: implications for selection of adjuvant chemotherapy. Nat Clin Pract Oncol 3 : 621-632. https://doi.org/10.1038/ncponc0636

30. Loibl S, Gianni L (2017) HER2-positive breast cancer. Lancet 389:2415-2429. https://doi.org/10.1016/S0140-6736(16)32417-5

31. Francis PA, Pagani O, Fleming GF et al (2018) Tailoring adjuvant endocrine therapy for premenopausal breast cancer. N Engl J Med 379:122-137. https://doi.org/10.1056/NEJMoa1803164

32. Davies C, Pan H, Godwin J et al (2013) Long-term effects of continuing adjuvant tamoxifen to 10 years versus stopping at 5 years after diagnosis of oestrogen receptor-positive breast cancer: ATLAS, a randomised trial. Lancet 381:805-816. https://doi.org/10.1016/S01406736(12)61963-1

33. Gray RG, Rea D, Handley K et al (2013) ATTom: Long-term effects of continuing adjuvant tamoxifen to 10 years versus stopping at 5 years in 6,953 women with early breast cancer. J Clin Oncol 31:5-5. https://doi.org/ 10.1200/jco.2013.31.18_suppl.5

34. Goss PE, Ingle JN, Martino S et al (2005) randomised trial of letrozole following tamoxifen as extended adjuvant therapy in receptor-positive breast cancer: updated findings from NCIC CTG MA.17. JNCI J Natl Cancer Inst 97:1262-1271. https://doi.org/10.1093/jnci/dji250

35. Mamounas EP, Jeong J-H, Wickerham DL et al (2008) Benefit from exemestane as extended adjuvant therapy after 5 years of adjuvant tamoxifen: intention-to-treat analysis of the National Surgical Adjuvant Breast and Bowel Project B-33 trial. J Clin Oncol 26:1965-1971. https://doi. org/10.1200/JCO.2007.14.0228

36. Goss PE, Ingle JN, Pritchard Kl et al (2016) Extending aromatase-inhibitor adjuvant therapy to 10 years. N Engl J Med 375:209-219. https://doi.org/10. 1056/NEJMoa1604700

37. Tjan-Heijnen VCG, van Hellemond IEG, Peer PGM et al (2017) Extended adjuvant aromatase inhibition after sequential endocrine therapy (DATA): randomised, phase 3 trial. Lancet Oncol 18:1502-1511. https://doi.org/10. 1016/S1470-2045(17)30600-9

38. Blok EJ, Kroep JR, Meershoek-Klein Kranenbarg E et al (2018) Optimal duration of extended adjuvant endocrine therapy for early breast cancer; results of the IDEAL trial (BOOG 2006-05). JNCI J Natl Cancer Inst 110:40-48. https://doi.org/10.1093/jnci/djx134

39. Mamounas EP, Bandos H, Lembersky BC et al (2019) Use of letrozole after aromatase inhibitor-based therapy in postmenopausal breast cancer (NRG Oncology/NSABP B-42): a randomised, double-blind, placebo-controlled, phase 3 trial. Lancet Oncol 20:88-99. https://doi.org/10.1016/S14702045(18)30621-1
40. Pan H, Gray R, Braybrooke J et al (2017) 20-year risks of breast-cancer recurrence after stopping endocrine therapy at 5 years. N Engl J Med 377: 1836-1846. https://doi.org/10.1056/NEJMoa1701830

41. Diéras $V$, Rugo HS, Schnell P et al (2019) Long-term pooled safety analysis of palbociclib in combination with endocrine therapy for HR+/HER2advanced breast cancer. JNCI J Natl Cancer Inst 111:419-430. https://doi. org/10.1093/jnci/djy109

42. A study of palbociclib in addition to standard endocrine treatment in hormone receptor positive HER2 normal patients with residual disease after neoadjuvant chemotherapy and surgery (PENELOPE-B). https://clinicaltrials. gov/ct2/show/study/NCT01864746. Accessed 31 August 2020

43. Endocrine therapy with or without abemaciclib (LY2835219) following surgery in participants with breast cancer (monarchE). https://clinicaltrials. gov/show/NCT03155997. Accessed 31 August 2020

44. A trial to evaluate efficacy and safety of ribociclib with endocrine therapy as adjuvant treatment in patients With HR+/HER2- early breast cancer (NATALEE). https://clinicaltrials.gov/show/NCT03701334. Accessed 31 August 2020

45. Moja L, Tagliabue L, Balduzzi S et al (2012) Trastuzumab containing regimens for early breast cancer. Cochrane Database Syst Rev 2012: CD006243. https://doi.org/10.1002/14651858.CD006243.pub2

46. von Minckwitz G, Procter M, de Azambuja E et al (2017) Adjuvant pertuzumab and trastuzumab in early HER2-positive breast cancer. N Engl J Med 377:122-131. https://doi.org/10.1056/NEJMoa1703643

47. Martin M, Holmes FA, Ejlertsen B et al (2017) Neratinib after trastuzumabbased adjuvant therapy in HER2-positive breast cancer (ExteNET): 5-year analysis of a randomised, double-blind, placebo-controlled, phase 3 trial. Lancet Oncol 18:1688-1700. https://doi.org/10.1016/S1470-2045(17)30717-9

48. Tolaney SM, Guo H, Pernas S et al (2019) Seven-year follow-up analysis of adjuvant paclitaxel and trastuzumab trial for node-negative, human epidermal growth factor receptor 2-positive breast cancer. J Clin Oncol 37: 1868-1875. https://doi.org/10.1200/JCO.19.00066

49. Cortazar P, Zhang L, Untch M et al (2014) Pathological complete response and long-term clinical benefit in breast cancer: the CTNeoBC pooled analysis. Lancet 384:164-172. https://doi.org/10.1016/S0140-6736(13)62422-8

50. Early Breast Cancer Trialists' Collaborative Group (EBCTCG) (2018) Long-term outcomes for neoadjuvant versus adjuvant chemotherapy in early breast cancer: meta-analysis of individual patient data from ten randomised trials. Lancet Oncol 19:27-39. https://doi.org/10.1016/S1470-2045(17)30777-5

51. Gianni L, Pienkowski T, Im Y-H et al (2016) 5-year analysis of neoadjuvant pertuzumab and trastuzumab in patients with locally advanced, inflammatory, or early-stage HER2-positive breast cancer (NeoSphere): a multicentre, open-label, phase 2 randomised trial. Lancet Oncol 17:791-800. https://doi.org/10.1016/S1470-2045(16)00163-7

52. Schneeweiss A, Chia S, Hickish T et al (2013) Pertuzumab plus trastuzumab in combination with standard neoadjuvant anthracycline-containing and anthracycline-free chemotherapy regimens in patients with HER2-positive early breast cancer: a randomised phase II cardiac safety study (TRYPHAEN A). Ann Oncol 24:2278-2284. https://doi.org/10.1093/annonc/mdt182

53. Burstein HJ, Curigliano G, Loibl S et al (2019) Estimating the benefits of therapy for early-stage breast cancer: the St. Gallen international consensus guidelines for the primary therapy of early breast cancer 2019. Ann Oncol 30:1541-1557. https://doi.org/10.1093/annonc/mdz235

54. Nanda R, Liu MC, Yau C et al (2017) Pembrolizumab plus standard neoadjuvant therapy for high-risk breast cancer (BC): Results from I-SPY 2. J Clin Oncol 35:506-506. https://doi.org/10.1200/JCO.2017.35.15_suppl.506

55. Schmid P, Cortes J, Pusztai L et al (2020) Pembrolizumab for early triplenegative breast cancer. N Engl J Med 382:810-821. https://doi.org/10.1056/ NEJMoa1910549

56. Gianni L, Huang C-S, Egle D et al (2020) Abstract GS3-04: Pathologic complete response ( $p C R$ ) to neoadjuvant treatment with or without atezolizumab in triple negative, early high-risk and locally advanced breast cancer. NeoTRIPaPDL1 Michelangelo randomised study. In: Proceedings of the 2019 San Antonio Breast Cancer Symposium; 2019 Dec 10-14; San Antonio, TX. Philadelphia (PA): AACR; Cancer Res 2020;80(4 Suppl):Abstract nr GS3-04. http://www.cancerres.aacrjournals.org/content/80/4_ Supplement/GS3-04.

57. Hennigs A, Riedel F, Marmé F et al (2016) Changes in chemotherapy usage and outcome of early breast cancer patients in the last decade. Breast Cancer Res Treat 160:491-499. https://doi.org/10.1007/s10549-0164016-4 
58. Cardoso F, van't Veer $\sqcup$, Bogaerts J et al (2016) 70-gene signature as an aid to treatment decisions in early-stage breast cancer. N Engl J Med 375:717729. https://doi.org/10.1056/NEJMoa1602253

59. Filipits $M$, Rudas $M$, Jakesz $R$ et al (2011) A new molecular predictor of distant recurrence in ER-positive, HER2-negative breast cancer adds independent information to conventional clinical risk factors. Clin Cancer Res 17:6012-6020. https://doi.org/10.1158/1078-0432.CCR-11-0926

60. Dubsky P, Brase JC, Jakesz R et al (2013) The EndoPredict score provides prognostic information on late distant metastases in ER+/HER2- breast cancer patients. Br J Cancer 109:2959-2964. https:/doi.org/10.1038/bjc.2013.671

61. Sgroi DC, Carney E, Zarrella E et al (2013) Prediction of late disease recurrence and extended adjuvant letrozole benefit by the HOXB13/LL17BR biomarker. JNCI J Natl Cancer Inst 105:1036-1042. https://doi.org/10.1093/jnci/djt146

62. Dowsett M, Sestak I, Lopez-Knowles E et al (2013) Comparison of PAM50 risk of recurrence score with Oncotype DX and $\mathrm{IHC} 4$ for predicting risk of distant recurrence after endocrine therapy. J Clin Oncol 31:2783-2790. https://doi.org/10.1200/JCO.2012.46.1558

63. Gnant M, Filipits M, Greil R et al (2014) Predicting distant recurrence in receptor-positive breast cancer patients with limited clinicopathological risk: using the PAM50 risk of recurrence score in 1478 postmenopausal patients of the ABCSG-8 trial treated with adjuvant endocrine therapy alone. Ann Oncol 25:339-345. https://doi.org/10.1093/annonc/mdt494

64. Paik S, Tang G, Shak S et al (2006) Gene expression and benefit of chemotherapy in women with node-negative, estrogen receptor-positive breast cancer. J Clin Oncol 24:3726-3734. https://doi.org/10.1200/JCO.2005. 04.7985

65. Sparano JA, Gray RJ, Makower DF et al (2018) Adjuvant chemotherapy guided by a 21-gene expression assay in breast cancer. N Engl J Med 379: 111-121. https://doi.org/10.1056/NEJMoa1804710

66. Gluz O, Nitz UA, Christgen M et al (2016) West German study group phase III planb trial: first prospective outcome data for the 21-gene recurrence score assay and concordance of prognostic markers by central and local pathology assessment. J Clin Oncol 34:2341-2349. https://doi.org/10.1200/ JCO.2015.63.5383

67. Gonzalez-Angulo AM, Barlow WE, Gralow J et al (2011) SWOG S1007: A phase III, randomised clinical trial of standard adjuvant endocrine therapy with or without chemotherapy in patients with one to three positive nodes, hormone receptor (HR)-positive, and HER2-negative breast cancer with recurrence score (RS). J Clin Oncol 29:TPS104-TPS104. https://doi.org/10. 1200/jco.2011.29.15_suppl.tps104

68. Berry DA, Cronin KA, Plevritis SK et al (2005) Effect of screening and adjuvant therapy on mortality from breast cancer. N Engl J Med 353:17841792. https://doi.org/10.1056/NEJMoa050518

69. Saadatmand S, Bretveld R, Siesling S, Tilanus-Linthorst MMA (2015) Influence of tumour stage at breast cancer detection on survival in modern times: population based study in 173797 patients. BMJ 351:h4901. https://doi.org/ 10.1136/bmj.h4901

70. Alabousi M, Zha N, Salameh J et al (2020) Digital breast tomosynthesis for breast cancer detection: a diagnostic test accuracy systematic review and meta-analysis. Eur Radiol 30:2058-2071. https://doi.org/10.1007/s00330-01906549-2

71. Hovda T, Holen ÅS, Lång $\mathrm{K}$ et al (2020) Interval and consecutive round breast cancer after digital breast tomosynthesis and synthetic 2D mammography versus standard 2D digital mammography in BreastScreen Norway. Radiology 294:256-264. https://doi.org/10.1148/ radiol.2019191337

72. Bernardi D, Gentilini MA, De Nisi M et al (2020) Effect of implementing digital breast tomosynthesis (DBT) instead of mammography on population screening outcomes including interval cancer rates: Results of the Trento DBT pilot evaluation. Breast 50:135-140. https://doi.org/10.1016/j.breast. 2019.09.012

73. Conant EF, Barlow WE, Herschorn SD et al (2019) Association of digital breast tomosynthesis vs digital mammography with cancer detection and recall rates by age and breast density. JAMA Oncol 5:635-642. https://doi. org/10.1001/jamaoncol.2018.7078

74. Bakker MF, de Lange SV, Pijnappel RM et al (2019) Supplemental MRI screening for women with extremely dense breast tissue. N Engl J Med 381: 2091-2102. https://doi.org/10.1056/NEJMoa1903986

75. Zanardo M, Cozzi A, Trimboli RM et al (2019) Technique, protocols and adverse reactions for contrast-enhanced spectral mammography (CESM): a systematic review. Insights Imaging 10:76. https://doi.org/10.1186/s13244-019-0756-0
76. Cozzi A, Schiaffino S, Sardanelli F (2019) The emerging role of contrastenhanced mammography. Quant Imaging Med Surg 9:2012-2018. https:// doi.org/10.21037/qims.2019.11.09

77. Ghaderi KF, Phillips J, Perry H et al (2019) Contrast-enhanced mammography: current applications and future directions. Radiographics 39:1907-1920. https://doi.org/10.1148/rg.2019190079

78. European Society of Radiology (ESR) (2019) Impact of artificial intelligence on radiology: a EuroAIM survey among members of the European Society of Radiology. Insights Imaging 10:105. https://doi.org/10.1186/s13244-0190798-3

79. McKinney SM, Sieniek M, Godbole V et al (2020) International evaluation of an Al system for breast cancer screening. Nature 577:89-94. https://doi.org/ 10.1038/s41586-019-1799-6

80. Pisano ED (2020) Al shows promise for breast cancer screening. Nature 577: 35-36. https://doi.org/10.1038/d41586-019-03822-8

81. Sardanelli $F$ (2017) Trends in radiology and experimental research. Eur Radiol Exp 1:1. https://doi.org/10.1186/s41747-017-0006-5

82. Neri E, Del Re M, Paiar F et al (2018) Radiomics and liquid biopsy in oncology: the holons of systems medicine. Insights Imaging 9:915-924. https://doi.org/10.1007/s13244-018-0657-7

83. Underwood JJ, Quadri RS, Kalva SP et al (2020) Liquid biopsy for cancer: review and implications for the radiologist. Radiology 294:5-17. https://doi. org/10.1148/radiol.2019182584

\section{Publisher's Note}

Springer Nature remains neutral with regard to jurisdictional claims in published maps and institutional affiliations.

\section{Submit your manuscript to a SpringerOpen ${ }^{\circ}$ journal and benefit from:}

- Convenient online submission

- Rigorous peer review

- Open access: articles freely available online

High visibility within the field

- Retaining the copyright to your article

Submit your next manuscript at $\boldsymbol{\nabla}$ springeropen.com 